Artigo original

Hegemonia - Revista Eletrônica de Relações Internacionais do Centro Universitário Unieuro

ISSN: $1809-1261$

UNIEURO, Brasília, número 20, Janeiro-Junho de 2017, pp. 89-119.

Recebido em: 4/11/2016

Avaliado em: 12/12/2016

Aprovado em: 26/12/2016

\title{
IIRSA y ZICOSUR en el Norte Argentino: ¿Infraestructura para la integración o integración para la infraestructura?
}

\author{
Macarena Mercado Mott ${ }^{1}$ e Senilde Alcântara Guanaes ${ }^{2}$
}

Resumen: El presente artículo se enfoca en identificar los proyectos de integración por infraestructura planificados para la región del Norte Argentino. A partir de la exposición de estas obras, que buscan conectar territorios en el marco de una lógica capitalista, se pretende problematizar el papel de los modelos de integración y desarrollo en la región. Se realiza una explicación de la Zona de Integración del Centro Oeste Suramericano (ZICOSUR) y su vinculación con la Iniciativa para la Integración por Infraestructura Suramericana (IIRSA) en el área de influencia del Norte Argentino. El objetivo de problematizar estos proyectos se encuadra en la explicación de los intereses que los promueven y de las consecuencias que pueden observarse a partir de quiénes son los beneficiados y los afectados por estos emprendimientos.

Palabras-clave: Integración, Territorios, ZICOSUR, IIRSA.

\footnotetext{
${ }^{1}$ Maestría en Integración Contemporánea en América Latina, ICAL, Línea de Investigación: Integración, Cultura y Sociedad.

2 Docente da Universidade Federal da Integração Latino Americana (UNILA), dos cursos de Antropologia e do Programa de Mestrado em Integração Contemporânea na América Latina. E-mail: seguanaes@gmail.com.
} 
Hegemonia - Revista Eletrônica de Relações Internacionais do Centro Universitário Unieuro

ISSN: $1809-1261$

UNIEURO, Brasília, número 20, Janeiro-Junho de 2017, pp. 89-119.

Resumo: O presente artigo enfoca-se em identificar os projetos de integração por infraestrutura planejados para a região Norte da Argentina. A partir da exposição dessas obras, que buscam conectar territórios no marco de uma lógica capitalista, pretende-se problematizar o papel dos modelos de integração e desenvolvimento da região. Realiza-se uma explicação da Zona de Integração do Centro Oeste Sul-Americano (ZICOSUR) e sua vinculação com a Iniciativa para a Integração da Infraestrutura Regional Sul-Americana (IIRSA) na área de influência do norte argentino. O objetivo de problematizar estes projetos enquadra-se na explicação dos interesses que os promovem e as consequências que podem ser observadas a partir dos beneficiários e os afetados por estes empreendimentos.

Palavras-Chave: Integração, Territórios, ZICOSUR, IIRSA.

Abstract: The present article focuses on the identification of the integration projects of infrastructure planned for the Northern Region of Argentina. Starting from the exhibition of these works -that attempt to connect territories into the frame of a capitalist logic- this work problematizes the role of the integration and development models in the Region. An explanation of the Integration Zone of the West Central of South America (ZICOSUR) is exposed, as well as its entailment to the Integration Initiative from the South American Infrastructure (IIRSA) in the area of influence of Northern Argentina. The objective of problematizing these projects is based on the explanation of the interests that promote them and the consequences that can be observed taking account the beneficiaries and the affected people by these ventures.

Keywords: Integration, Territories, ZICOSUR, IIRSA.

Introducción

Desde inicio del siglo XXI en la agenda de integración suramericana el eje de infraestructura es uno de los más relevantes y con mayor consenso entre los gobiernos y empresarios de la región. Sin embargo, las poblaciones que habitan - y subsistente - en esos territorios, no son consideradas. Las lógicas corporativas de las empresas y el papel que juega el Estado para volver esos territorios competitivos, productores de ganancia, sea para la instalación de emprendimientos extractivistas o la construcción de mega obras de infraestructura, comienzan a tener lugar en organismos como UNASUR, MERCOSUR e incluso instancias bilaterales, buscando la concreción de ciertas obras. 
Artigo original

Hegemonia - Revista Eletrônica de Relações Internacionais do Centro Universitário Unieuro

ISSN: 1809-1261

UNIEURO, Brasília, número 20, Janeiro-Junho de 2017, pp. 89-119.

Así, se construye la hipótesis del trabajo, planteando que la integración física es un instrumento para llevar a cabo la infraestructura necesaria para los mercados, siendo esta funcional a la profundización del modelo extractivo-exportador en la región. Es decir, nos encontramos frente a un modelo de integración extractivista/neoextractivista, dependiendo del tipo de gobierno que la promueva ("neoliberal” o "progresista”).

El recorte espacial se enfoca en el Norte Argentino, debido a que esta región además de pertenecer a la ZICOSUR y encontrarse en los planos de la IIRSA, pertenece a un país donde la última reforma de la Constitución Nacional realizada en 1994, modifica algunas competencias de las provincias (unidades subnacionales) como por ejemplo: el dominio de los recursos naturales y el poder realizar relaciones exteriores.

Estos elementos invitan a pensar la integración por unidades subnacionales, la primarización de las economías y los planes de infraestructura, porque es precisamente desde los años 90, duramente la presidencia de Carlos Saúl Menem, que el extractivismo y las reuniones con otros países y bancos de desarrollo, han comenzado a aumentar. Así, entendemos que es relevante tomar como caso de estudio las provincias argentinas debido a que nos interesa estudiar una zona de integración donde los actores son precisamente unidades subnacionales.

Presentamos de forma analítica los perfiles productivos exportadores de las provincias escogidas, buscando exponer la característica primaria-extractiva exportadora de esas economías norteñas, las cuales limitan con Chile, Bolivia, Paraguay y Brasil. También nos interesa mostrar cuáles son los países con los que esas provincias mantienen relaciones comerciales y los proyectos de infraestructura pensados para atravesar la Cordillera de los Andes, buscando los puertos chilenos con salida al Pacifico.

En síntesis, pretendemos estudiar esta región como una pieza del gran rompecabezas que (des)arma el capitalismo, y cómo estos territorios tienen su función en las cadenas de valor global, entendiendo a quienes interesa y a quienes beneficia la ingeniería institucional, civil y comercial pensada y desarrollada en la región. 
Artigo original

Hegemonia - Revista Eletrônica de Relações Internacionais do Centro Universitário Unieuro

ISSN: 1809-1261

UNIEURO, Brasília, número 20, Janeiro-Junho de 2017, pp. 89-119.

Desarrollo

En el Norte Argentino se encuentran dos proyectos de integración planificados y ejecutados por actores hegemónicos, organizados a partir de intereses corporativos y con la finalidad de integrar territorios específicos para realizar obras de infraestructura determinadas. Estos proyectos de integración son la Iniciativa para la Integración por Infraestructura Suramericana (IIRSA) y la Zona de Integración del Centro Oeste Suramericano (ZICOSUR). Ambos proyectos tienen como área de influencia el Subcontinente Suramericano, desdibujando las fronteras de los Estados nacionales, con una visión regional del territorio.

En el caso de la IIRSA, se presenta en sus Ejes de Integración y Desarrollo ${ }^{3}$, los cuales incluyen territorios de diferentes países suramericanos. En cambio la ZICOSUR plantea una zona donde participan las unidades administrativas subnacionales de cada uno de esos Estados, planteando una herramienta para las relaciones exteriores de las provincias, estados, departamentos o regiones subnacionales de los países suramericanos. Al mismo tiempo que ese espacio es compartido -y dirigido- por representantes locales y empresarios de la región.

3 Los Ejes de Integración y Desarrollo (EIDs) son franjas multinacionales de territorio en donde se concentran espacios naturales, asentamientos humanos, zonas productivas y flujos comerciales. Para cada EID se identifican los requerimientos de infraestructura física, a fin de articular el territorio con el resto de la región, planificar las inversiones y mejorar la calidad de vida de sus habitantes. Los EIDs organizan el territorio suramericano y ordenan la Cartera de Proyectos. En IIRSA se han identificado diez EIDs: Andino, Andino del Sur, Capricornio, Hidrovía Paraguay- Paraná, Amazonas, Escudo Guayanés, Del Sur, Interoceánico Central, MERCOSUR-Chile, Perú-Brasil-Bolivia. Información disponible en línea: http://www.iirsa.org/infographic 
ISSN: $1809-1261$

UNIEURO, Brasília, número 20, Janeiro-Junho de 2017, pp. 89-119.

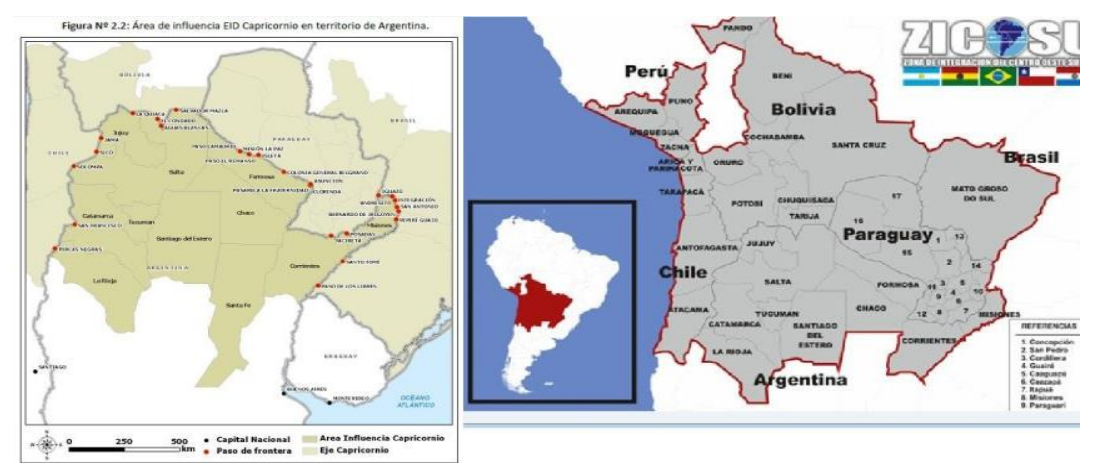

Fuente: elaboración propia a partir de las imágenes disponibles en los sitios oficiales de IIRSA y ZICOSUR

ZICOSUR: volviendo competitivos los territorios "periféricos de la periferia"

La ZICOSUR ${ }^{4}$ cuenta con una serie de antecedentes como lo son las experiencias de paradiplomacia a nivel regional, como los casos del Comité de Frontera Argentino- Chileno ${ }^{5}$ o macro-región ATACALAR ${ }^{6}$ y la Red de Ciudades Mercociudades ${ }^{7}$, los cuales traen consigo ciertas innovaciones en sus abordajes y conceptualizaciones.

\footnotetext{
${ }^{4}$ En la página oficial del organismo, se explica que el proyecto ZICOSUR se enriquece con la decidida participación de los gobiernos provinciales del área y comienza a tomar forma en el I Encuentro ZICOSUR Asia Pacífico, realizado en Antofagasta, Chile, en abril de 1997, por iniciativa de los gobiernos regionales, con la participación de embajadores y empresarios de distintos países asiáticos y de Oceanía. Es en el II Encuentro Internacional ZICOSUR - Asia Pacífico, realizado en la Provincia de Salta en 1998, cuando se decide dotar a la subregión de una estructura orgánica básica; a tal fin se acuerda la creación de un Grupo de Trabajo integrado por las autoridades políticas de cada Región, Provincia o Departamento adheridos a la ZICOSUR para diseñar programas de desarrollo compartido, políticas y acciones conducentes al afianzamiento de la ZICOSUR en el ámbito internacional de las inversiones, producción y comercialización. Estos Encuentros donde se reúnen los diferentes miembros, se han transformado en instancias donde priman los espacios de cooperación y acuerdo entre los gobiernos y el empresariado, así como de intercambio con los países de la Cuenca del Pacífico.

${ }^{5}$ Los Comités de Frontera que funcionan actualmente entre Chile y Argentina mantienen reuniones periódicas en las que se van abordando temas específicos relacionados con la facilitación del tránsito transfronterizo, aspectos aduaneros, migratorios, sanitarios y otros. También han constituido foros donde se recogen inquietudes regionales relacionadas con el desarrollo de las funciones de control fronterizo y la facilitación del tránsito terrestre binacional. Para ampliar información: http://www.difrol.gob.cl/argentina/comite-de-integracion-chileargentina.html

${ }^{6}$ Para ampliar información sobre ATACALAR: http://www.comiteatacalar.cl/

${ }^{7}$ Para ampliar información sobre Red Mercociudades: http://www.mercociudades.org/
} 
Hegemonia - Revista Eletrônica de Relações Internacionais do Centro Universitário Unieuro

ISSN: 1809-1261

UNIEURO, Brasília, número 20, Janeiro-Junho de 2017, pp. 89-119.

Estas propuestas de integración sub-regional que pueden encontrarse en el Cono Sur, se encuentran integradas por unidades políticas que consisten en jurisdicciones periféricas de los centros económicos y decisionales de sus países, por lo que el componente de las relaciones transfronterizas que mantienen muchas de ellas, significan potenciales vías de diálogo e interacción con sus vecinas.

ZICOSUR es un claro ejemplo de la cooperación entre unidades políticas de diferentes Estados que por tener intereses en común, se integran en aspectos económicos y políticos en una subregión encuadrada dentro del marco y la lógica del MERCOSUR. Son seis los países del Cono Sur que comparten este proyecto común, Argentina, Bolivia, Chile, Paraguay, Brasil y Perú, teniendo como ejes central tres corredores bioceánicos ${ }^{8}$ : Corredor del Norte (Arica - La Paz - Santa Cruz de la Sierra - Puerto Suárez - Corumbá, sistema vial brasileño - Sao Paulo), Corredor del Trópico de Capricornio (Antofagasta - Mejillones - Tocopilla - Calama - San Pedro de Atacama - Paso de Jama- Jujuy - Tartagal - Pozo Hondo -Mariscal Estigarribia -Filadelfia Puerto Murtinho - Campo Grande, sistema vial brasileño, Sao Paulo. También se conectan caminos desde Tarija y Potosí. Además permite conectar con la ruta internacional Brasil Venezuela - Colombia) y Corredor del Sur (Antofagasta - Tocopilla - Mejillones- Calama - Paso de Sico, Salta, Metan, Resistencia, Clorinda, Asunción y Concepción- Ponta Porá - Dourados, sistema vial brasileño- Sao Paulo).

Para la Zona ZICOSUR, los corredores priorizados y otros alternativos buscan fundamentalmente combinar a las provincias de las zonas que la integran puertos del norte de Chile como Antofagasta, Iquique y /o Arica. En Argentina, Corrientes, Chaco, Misiones, Formosa, Santiago del Estero, Tucumán, Salta, Jujuy, Catamarca, La Rioja y norte de Santa Fe,

\footnotetext{
${ }^{8}$ En el sitio oficial sobre los corredores de la ZICOSUR se explica que un corredor bioceánico comprende una franja de territorio dentro de la cual se desarrolla un sistema vial, ferroviario e hidroviario con objetivos estratégicos económicos, sociales y políticos. Estos tienen como finalidad lograr un espacio con una infraestructura integral de transporte que facilite el flujo y movimiento de bienes y personas y permita concretar, al menor costo, las operaciones de comercio interior y exterior, a través de una comunicación entre el Atlántico y el Pacífico. Estos proyectos son viables debido a la participación de tres modalidades de transporte (vial, ferroviario y fluvial). De esta manera se facilita la salida de las producciones hacia países limítrofes con menores costos operativos de transporte y una reducción en los tiempos de viaje. Disponible en línea: http://zicosur.info/corredor.html
} 
Artigo original

Hegemonia - Revista Eletrônica de Relações Internacionais do Centro Universitário Unieuro

ISSN: 1809-1261

UNIEURO, Brasília, número 20, Janeiro-Junho de 2017, pp. 89-119.

incluyendo al NOA y NEA. En Brasil, zonas de Foz do Iguazu, Cascavel, Curitiva, para llegar al Atlántico al Puerto de Paranagua o bien a los puertos de Porto Alegre, Santos , San Francisco Do Soul o Florianapolis.

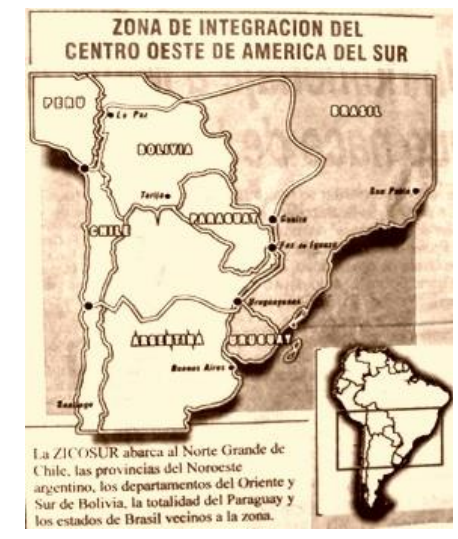

Fuente: Biblioteca de Salta (provincia del noroeste argentino)

La ZICOSUR se encuentra entre los fenómenos donde participan actores como los estados subnacionales, que Mercedes Botto (2004) explica como actores que comienzan a participar con voz propia en los foros y negociaciones internacionales. Los procesos de descentralización estatal que han otorgado mayor protagonismo a los gobiernos subnacionales, al mismo tiempo que ampliaron sus facultades y horizontes de acción, son principalmente en el ámbito de la economía, la cooperación y, en menor medida, en temas de seguridad; como lo expone Merlo Blázquez (2011). En el caso de las provincias argentinas, las mismas poseen ciertas competencias que les permiten realizar este tipo de acciones políticas.

En este marco es importante considerar como base sustancial de estos proyectos por un lado, el "Pacto Federal" firmado entre el gobierno nacional y las provincias argentinas de mayo de 1990 que reconoce a las provincias en su Art.5 "el derecho a realizar gestiones y acuerdos en el orden internacional para satisfacción de sus intereses locales sin lesionar las atribuciones constitucionales que, en materia de política exterior le corresponden al Estado Nacional". Y por otro, en línea con lo anterior, el art.124 de la Constitución de 1994 en el que se establece que "Las provincias podrán crear regiones para el desarrollo económico y social y establecer órganos con facultades para el cumplimiento de sus fines y podrán celebrar convenios internacionales en tanto no sean incompatibles con la política exterior de la Nación y no afecten las facultades delegadas al Gobierno Federal" (CARLINO, VEIRAVÉ, 2003, p. 1). 
Hegemonia - Revista Eletrônica de Relações Internacionais do Centro Universitário Unieuro

ISSN: $1809-1261$

UNIEURO, Brasília, número 20, Janeiro-Junho de 2017, pp. 89-119.

Este proyecto integracionista tiene como antecedente inmediato las iniciativas que surgieron del sector privado coordinado con el público, generando su mayor impulso en la década del '90. Son varias las versiones respecto al origen de ZICOSUR, y los actores que motivaron la creación de este modelo de integración entre unidades sudnacionales.

Una de las versiones, sostiene que fue idea de la Secretaría Regional de Integración del Gobierno Regional de Antofagasta (Segunda Región, Chile), creada en 1995 como una Comisión Asesora del Intendente Regional, que en cumplimiento de sus objetivos y en el marco de sus funciones formuló dicho proyecto. En ese sentido Vazquez Palacio (2008) explica que la zona que da el primer impulso formal a la ZICOSUR es la Región Chilena de Antofagasta, con su nuevo megapuerto de Mejillones, sobre la que construyó la imagen de "ventana al Asia", mediante conexiones marítimas importantes en términos de volúmenes y proximidad geográfica.

No podemos dejar de mencionar que la ZICOSUR "institucionalmente tiene su antecedente inmediato en el Grupo Empresarial Interregional del Centro-Oeste Sudamericano (GEICOS), creado en 1977 como consecuencia de los Encuentros de Integración Regionales Fronterizos realizados en Salta, Argentina, en el marco de la Feria Internacional del Norte Argentino (FERINOA)" (CARLINO, VEIRAVÉ, 2003, p. 8). Este grupo "que integra a los emprendedores de los países en cuestión, funcionan en red desde antes del nacimiento de la Zicosur, en 1997, y deben ser reconocidos como los pívots de la Zicosur actual" (VAZQUEZ PALACIO, 2008, p.231).

GEICOS ha estructurado una dinámica impresionante. Este actor promovió la Zona de Integración del Centro Oeste de Suramérica, ZICOSUR, que apunta a mancomunar la II región de Antofagasta, con las Provincias del Norte de Argentina, los Departamentos sureños bolivianos, la República de Paraguay y los Estados del Oeste brasileño. De sus acuerdos han nacido importantes inversiones en Obras Públicas para caminos internacionales que facilitan el comercio (GARRIDO ROJAS, 2001, p. 47).

Garrido Rojas (2001) menciona que GEICOS es la más informal y antigua de las agrupaciones de países latinoamericanos; fundamentalmente creada por empresarios privados; que han incluido a las Universidades de la subregión y han contado con el apoyo gubernamental. 
Artigo original

Hegemonia - Revista Eletrônica de Relações Internacionais do Centro Universitário Unieuro

ISSN: $1809-1261$

UNIEURO, Brasília, número 20, Janeiro-Junho de 2017, pp. 89-119.

El grupo empresarial es el más parecido al modelo de regionalismo abierto desarrollado por los países asiáticos, en contraposición del "regionalismo cerrado" ejemplificado en la Unión Europea. Está conformado por empresarios y universidades del noroeste de Argentina, Bolivia, Paraguay, Sur del Perú y las Regiones I y II de Chile. Desde hace más de dos décadas se reúnen en diferentes puntos de los países miembros (GARRIDO ROJAS, 2001, p. 46).

Al comenzar a identificar los orígenes de ZICOSUR, encontramos como el papel del Estado -en este caso subnacional- se encuentra más claro. Como lo explica Milton Santos (2000) donde expone que el Estado no está ausente, ni es menor que antes. "El Estado sólo se omite respecto a los intereses de la población y se vuelve fuerte y aún más ágil y presente, al servicio de la economía dominante" (SANTOS, 2000, p.66). Continúa afirmando que la política ahora es hecha en el mercado. Sólo que ese mercado global no existe como actor, sino como una ideología, un símbolo.

Los actores son las empresas globales, que no tienen preocupaciones éticas, ni finalistas. En el mundo de la competitividad, o se es cada vez más individualista, o se desaparece. Entonces, la propia lógica de la supervivencia de la empresa global sugiere que funcione sin ningún altruismo. Sin embargo, si el Estado no puede ser solidario y la empresa no puede ser altruista (SANTOS, 2000, p.67).

Una expresión de esta "región virtual” es la Secretaria Regional de Integración por el Gobierno Regional de Antofagasta, Chile, por resolución exenta $N^{\circ} 174$ del 3 de mayo de 1995. Con vistas a que ZICOSUR sea un punto de salida hacia el Pacífico de Corredores Comerciales bi o tri nacionales.

Con una parte del sistema de infraestructura de comunicación, Chile hace un
llamado a la periferia del Mercosur con un nuevo modelo, alternativo al histórico del
Mercosur y del Río de la Plata, de integración mundial del continente sudamericano,
que ya no está obligado a integrarse hacia el Este y Europa, testimoniando más de
cinco siglos de dependencia de los diversos imperios europeos. Por el contrario, se
movilizan un conjunto de imaginarios de integración y conexión inéditos para los
periféricos, la integración al mundo se puede materializar hacia el Oeste, el océano
Pacifico y, especialmente, con los tigres asiáticos, modelos exitosos del salto
tecnológico y la generación de riqueza (VAZQUEZ PALACIO, 2008 p.231).

Esto constituye una ruptura mayor con la imagen, estructura y actores del modelo de desarrollo e integración que las regiones periféricas de los países conocían y aspiraban hasta entonces: la incorporación de los espacios periféricos al desarrollo nacional y del desarrollo nacional equilibrado al Mercosur y de este al Mundo, pasando siempre por el océano Atlántico, 
Artigo original

Hegemonia - Revista Eletrônica de Relações Internacionais do Centro Universitário Unieuro

ISSN: $1809-1261$

UNIEURO, Brasília, número 20, Janeiro-Junho de 2017, pp. 89-119.

con los socios comerciales tradicionales. Sin embargo, el análisis de este proceso integracionista es caracterizado por Amilhat Szary en Vazquez Palacio (2008) como "retórico, pues el discurso movilizado sobre la integración, construido desde Chile, presenta a sus regiones del Norte como "puente entre el Sudeste asiático y los países sudamericanos" (VAZQUEZ PALACIO, 2008 p.231).

Una segunda versión respecto al origen de ZICOSUR, la presenta Alejandro Gabriel Safarov (2003) como una iniciativa diagramada por economistas y académicos japoneses con el patrocinio de la Fundación OKITA ${ }^{9}$. Afirma que la integración con Chile a través de pasos cordilleranos carreteros alternativos al norte de la provincia de Mendoza no es idea reciente en el país, ya que en la década del '70 del siglo XX ya existían proyectos como los de la Comisión Ferro-vial Paso de Jama (Jujuy); luego, en la década de los '80 aquella vinculación a Chile fue aconsejada por el "Estudio sobre el Desarrollo Económico de la República Argentina” que también eran propuestas del Plan OKITA.

Lo novedoso quizás haya sido, sumar a aquel viejo anhelo, otra idea también añeja: la vinculación Atlántico-Pacífico uniendo Brasil, Paraguay y Bolivia a través de esos pasos. Y esa intención, sí es posible rastrearla de manera explícita en el "Estudio sobre el Desarrollo Económico de la República Argentina, Respuesta Argentina” y con mayor claridad en el "Segundo Estudio" (Informe Kawai) realizado por la JICA.

Safarov (2003) explica el rol de la Segunda Región de Chile, como la encargada de vehiculizar la idea surgida de los proyectos señalados; asumiendo la tarea de conciliar la voluntad política de las regiones integradas al proyecto y a través de contactos directos logró concretar una primera reunión Zicosur-Asia Pacífico, realizada en Antofagasta en 1997.

9 Vigilio Tedín Uriburu, director ejecutivo de la Fundación Okita, comenta en una entrevista que la misma consiste en una organización sin fines de lucro dedicada a fomentar las relaciones integrales entre la Argentina y los países de la región del Asia Pacífico, Oceanía e India.

Son objetivos de la entidad promover, estimular y realizar estudios económicos y estratégicos que tengan por finalidad incrementar las relaciones entre la Argentina y los países de Asia Pacífico, Oceanía e India, especialmente a través de la detección de oportunidades de inversión y comercio.

Con el propósito de cumplir con sus objetivos, la Fundación Okita lleva a cabo diversas actividades, tales como la publicación de perfiles económicos acerca de los distintos países de interés, estudios sobre las posibilidades de incrementar hacia dichos países las exportaciones de productos argentinos y también realiza seminarios con expertos nacionales y extranjeros (URIBURU, 2008). 
Hegemonia - Revista Eletrônica de Relações Internacionais do Centro Universitário Unieuro

ISSN: 1809-1261

UNIEURO, Brasília, número 20, Janeiro-Junho de 2017, pp. 89-119.

Ofelia Stahringer en Nalvanti et. al (2012) expone que en el caso de ZICOSUR, se está frente a un proceso de regionalización horizontal en base a concertación política, por influencia de intereses compartidos. La autora identifica de dos grandes grupos de intereses que motivaron el acuerdo político: el de las regiones mediterráneas y el de las regiones con costas en el Pacifico.

Entre las regiones mediterráneas se encuentra el Norte Grande Argentino, Bolivia, Paraguay y Estados de Brasil, los cuales ven en la ZICOSUR una forma de encontrar una salida al mar para sus productos, utilizando los corredores bioceánicos. En segunda instancia, expone a las regiones adyacentes al Pacifico, regiones del Norte de Chile y los departamentos del sur Peruano, afirmando que pretenden revitalizar sus economías mediante el desarrollo de un conjunto de servicios necesarios para el comercio exterior (CARLINO, VEIRAVÉ, 2003).

Continuando con la indagación respecto a los estímulos endógenos o exógenos que propiciaron la creación de ZICOSUR, Botto (2004) plantea que en el contexto latinoamericano y en el argentino en particular, la discusión académica y política en torno a la paradiplomacia subnacional se ha concentrado en la identificación de los factores domésticos que explican los procesos de internacionalización de las provincias, en la construcción de una nueva institucionalidad subnacional y en los consecuencias que esta creciente autonomía subnacional genera sobre la diplomacia nacional.

Vazquez Palacio (2008) expone que ZICOSUR comenzó a federar a otras regiones “desencantadas" de sus respectivos países, y se expandió más allá de los límites naturales del Gran Chaco.

El estado brasileño de Matto Grosso se adhirió a la iniciativa con la estrategia de conectarse, y conectar al Brasil entero con los puertos del Pacifico. En el caso de Paraguay, la totalidad de los departamentos de la región Oriental, son considerados miembros, sólo porque los corredores pasan por esta región, en este caso, la ecuación entre Zicosur y corredores de integración no se resuelve tan mecánicamente. Esto conlleva el riesgo de conformar una mega región "dormida" o perdedora que generá adhesión sin producción (VAZQUEZ PALACIO, 2008, p.230). 
Artigo original

Hegemonia - Revista Eletrônica de Relações Internacionais do Centro Universitário Unieuro

ISSN: 1809-1261

UNIEURO, Brasília, número 20, Janeiro-Junho de 2017, pp. 89-119.

Contexto neoliberal, regionalismo abierto y nuevo regionalismo

ZICOSUR tiene sus orígenes en un contexto particular que atravesó la región. Durante los años 90, en general, América Latina era foco de implementación de políticas neoliberales, diseñadas a partir del Consenso de Washington, para desmantelar lo público, achicar al Estado y generar niveles de desigualdad que hasta la actualidad no han podido solucionarse.

Argentina, y sus gobiernos, no fueron la excepción a la aplicación de estas medidas y a los efectos que trajo esa época neoliberal, la cual también se encontró caracterizada por las propuestas cepalinas respecto al Regionalismo Abierto.

La CEPAL concebía a la integración como un proceso esencialmente comercial, en particular basado en las rebajas arancelarias y apertura de los mercados nacionales al exterior. La liberalización no sólo era dentro de una región sino al mundo, suponiéndose que operarían mecanismos de competitividad convencionales que permitirían una mejor inserción exportadora (GUDYNAS, 2005).

Respecto a los objetivos relacionados a Infraestructura y Servicios se presentan los de Promover la interconexión de las hidrovías Paraguay-Paraná y Paraná-Tieté con la Red de Comunicaciones Bioceánicas como arterias principales de comunicación; Desarrollar esquemas de Transporte Multimodales potenciando el ferroviario inmerso en el trazado y utilización del Corredor Bioceanico Norte-Pacífico-Atántico, a través del desarrollo de proyectos y su financiamiento; Lograr la progresiva integración energética promoviendo inversiones en Complejos Energéticos y Gasíferos de la Región (Bolivia - Argentina - Brasil); Optimizar los pasos fronterizos, desburocratizando y agilizando los organismos de control fronterizo en los países integrantes de la subregión (ZICOSUR, 2016, grifo nosso).

Algunos autores proponen como solución para terminar con las condiciones de periferia de la región, el camino hacia mayor infraestructura física, buscando eliminar barreras que caracterizan a la región.

Montenegro y Sommer (2008) consideran que Sudamérica tiene debilidades estructurales de características geográficas, su territorio regional se encuentra fragmentado por barreras que impiden el acceso a los recursos naturales y el suministro de bienes y servicios a 
Artigo original

Hegemonia - Revista Eletrônica de Relações Internacionais do Centro Universitário Unieuro

ISSN: 1809-1261

UNIEURO, Brasília, número 20, Janeiro-Junho de 2017, pp. 89-119.

bajo costo. Ante esto proponen - al igual que otros autores- que los gobiernos encuentren respuestas eficaces para gestionar y ampliar la infraestructura física, para no obstaculizar el desarrollo, la integración y la participación de la región en el proceso de globalización.

IIRSA y ZICOSUR: el mismo camino hacia la integración para la infraestructura

En el marco del Regionalismo Abierto, se propone el desarrollo de infraestructura regional. Desde esta perspectiva la IIRSA es definida por Montenegro et al. (2008) como una iniciativa multinacional, multisectorial y multidisciplinaria, que contempla mecanismos de coordinación entre gobiernos (en sus diferentes niveles), organismos internacionales y el sector privado. Teniendo en cuenta que estos proyectos se plantean como principal objetivo aumentar la competitividad de la región.

En el encuentro de jefes de estado de América del Sur, que se realizó en Brasilia en el año 2000, el presidente brasileño Fernando Cardoso propuso impulsar el mejoramiento de las infraestructuras de comunicación, dando origen a la IIRSA.

Para la Zicosur, el IIRSA representa una gran oportunidad para la paliar el gran déficit de infraestructura de comunicaciones, disminuyendo así, en parte, el handicap del aislamiento y la marginación. Entre los diversos ejes de comunicación del IIRSA, el llamado Eje Capricornio, por la línea de latitud sobre la cual se encuentra, tendrá una gran trascendencia económica para las regiones "interiores" de la Zicosur, especialmente a los departamentos del Chaco paraguayo y a los departamentos bolivianos de Tarija, Chuquisaca y Santa Cruz (VAZQUEZ PALACIO, 2008, p.234).

Quien analice los procesos de integración desde una perspectiva de la infraestructura, podría afirmar como Vazquez Palacio (2008) que los corredores bioceánicos tienen una relevancia estratégica continental para los países sudamericanos, para las zonas de la ZICOSUR, ya que estas tienen un rol central en la reconfiguración territorial. Sin embargo, al mismo tiempo, el autor plantea que las rutas son importantes pero no suficientes para desencadenar procesos de desarrollo,

[...] debe alertar a las zonas que serán activadas por las rutas y demás infraestructuras logísticas, sobre los serios riesgos relacionados al "efecto túnel" donde los territorios marginales actuales se convierten sólo en el soporte físico de la infraestructura, pues los flujos transportados no generan más que actividades secundarias y pasajeras, sin generación de valor agregado a la producción zonal. La 
Artigo original

Hegemonia - Revista Eletrônica de Relações Internacionais do Centro Universitário Unieuro

ISSN: $1809-1261$

UNIEURO, Brasília, número 20, Janeiro-Junho de 2017, pp. 89-119.

construcción de procesos de desarrollo regional y local, basados exclusivamente en la provisión de servicios logísticos no parece realista, por lo que además de la dotación de ciertos servicios vinculados al transporte y las comunicaciones, las regiones zicosurianas se encuentran ante la oportunidad estratégica de definir los modelos de inserción regional y mundial, aunque con la pesada carga de la marginación nacional y el déficit estructural que acarrean. El impulso de las infraestructuras de los proyectos del IIRSA debe ser concebida como la imperiosa necesidad de integración continental con una marcada proyección mundial, entendida ésta como un nuevo escenario de productos, mercados y actores cada vez más abierto y competitivo (VAZQUEZ PALACIO, 2008, p. 234 - 235).

Los proyectos son tradicionalmente financiados por el Estado, recurriendo a una combinación de préstamos de organismos internacionales de desarrollo, recursos propios y transferencia interna del sector y por medio de deuda interna por la vía de colocación de bonos del tesoro. Si bien la construcción de rutas y complejos fronterizos es responsabilidad del gobierno nacional, se trata de instancias en las cuales son los gobiernos provinciales los que proponen al gobierno nacional la realización de las obras y las ejecutan usando recursos propios y asignando las tareas a organismos provinciales.

Uso corporativo del territorio: despliegue de la ZICOSUR y la IIRSA en el Norte argentino

Para poder problematizar sobre el uso corporativo del territorio de la región ${ }^{10}$ del noroeste argentino, es necesario describir las características del espacio, a partir de lo que Milton Santos (2013, p. 86) propone entender como "un conjunto de sistemas de objetos y sistemas de acciones. Aclarando que los sistemas de objetos no funcionan si se los ve separados del sistema de acciones, y viceversa”. Además explica que el espacio hoy es un sistema de objetos cada vez más artificial, generado por sistemas de acciones también artificiales.

En este caso, nos referimos a las obras de infraestructuras planificadas para determinada región. Donde podemos acordar con Santos (2013) que las mismas “son objetos

10 Cuando nos referimos a Región, partimos de lo expuesto por Milton Santos, donde explica que actualmente se está lejos de la solidaridad orgánica que era propia de la definición del fenómeno regional. Pues actualmente las regiones son solidaridades organizacionales, espacios organizacionales, creadores de cohesión organizacional basadas en racionalidades de origen distante (SANTOS, 2013, p. 88). En el mismo texto, define a región (SANTOS, 2013, p.94) como subdivisiones del espacio: del espacio total nacional o del espacio local. Las regiones son un espacio de conveniencia, simples lugares funcionales al todo. 
Artigo original

Hegemonia - Revista Eletrônica de Relações Internacionais do Centro Universitário Unieuro

ISSN: $1809-1261$

UNIEURO, Brasília, número 20, Janeiro-Junho de 2017, pp. 89-119.

técnicos, que representan sistemas técnicos, dotados de una mecánica propia. Esos sistemas técnicos contemporáneos hegemónicos son dotados de una fuerza capaz de invadir cualquier otro sistema ya instalado, estableciendo sobre la tierra un área de combate que es, al mismo tiempo, la base de la dinámica de la dialéctica del espacio” (SANTOS, 2013, p. 87).

Así, podemos ver como lo natural y artificial caracterizan a determinado lugar que lo hace llamativo a que ciertos actores hagan un uso corporativo del territorio del mismo. Silveira (2011) explica que,

[...] cada momento histórico, o território de um país pode ser visto como um campo de forças que operam sobre formas "naturais" e artificiais. Mas estas formas têm um papel dinâmico, participando na produção de maiores densidades técnicas, informacionais e normativas. Todavia, se as formas são importantes, também o são as ações humanas, isto é, o comportamento no território das pessoas, das instituições, das empresas, determinando um dinamismo que varia segundo sua origem, sua força, sua intencionalidade, seus conflitos. O território usado é assim uma arena onde fatores de todas as ordens, independentemente da sua força, apesar de sua força desigual, contribuem à geração de situações. Em outras palavras, um território é um conjunto sincrônico de divisões do trabalho, não sem a hegemonia daquela fundada na técnica e na organização de mais alto desempenho (SILVEIRA, 2011, p. 4-5).

Así podemos identificar como los gobiernos locales que representan a las provincias del noroeste argentino, junto a los empresarios de la región -y otros externos a la mismaplanifican como usar el territorio, sus recursos, sin consultar a las comunidades o poblaciones locales. Las cuales son las más impactadas por las decisiones respecto a la construcción de determinadas obras de infraestructura y de grandes proyectos extractivistas. Esta situación podemos describirla como acumulación por desposesión. Categoría que propone David Harvey (2013) para explicar los fenómenos contemporáneos, sustituyendo el término de acumulación primitiva u original desarrollada por Marx,

Estão aí a mercadificação e a privatização da terra e a expulsão violenta de populações camponesas a conversão de várias formas de direitos de propriedade (comum, coletiva, do Estado, etc.) em dereitos exclusivos de propriedade privada; a supressão dos dereitos dos camponeses ás terras comuns (partilhadas); mercadificação da forca de trabalho e a supressão de formas alternativas (autóctones) de produção e de consumo; processos coloniais, neocoloniais e imperiais de apropriação de ativos (inclusive recursos naturais). [...] O Estado, com seu monopólio da violência e suas definições da legalidade, tem papel crucial no apoio e na promoção desses processos, havendo [...] consideráveis provas de que a transição para o desenvolvimento capitalista dependeu e continua a depender de maneira vital do agir do Estado. O papel desenvolvimentista do Estado começou há 
Artigo original

Hegemonia - Revista Eletrônica de Relações Internacionais do Centro Universitário Unieuro

ISSN: $1809-1261$

UNIEURO, Brasília, número 20, Janeiro-Junho de 2017, pp. 89-119.

muito tempo, e vem mantendo as lógicas territorial e capitalista do poder sempre interligadas, ainda que não necessariamente convergentes (HARVEY, 2013, p. 121).

Las provincias argentinas que forman parte de ZICOSUR, con la presencia de sus gobernadores como representantes son La Rioja, Catamarca, Tucumán, Santiago del Estero, Chaco, Corrientes, Misiones, Salta, Jujuy, Formosa.

Esta región de Argentina se caracteriza por ser una de las regiones más periféricas del país, con un nivel de satisfacción de las necesidades básicas muy bajo, altos niveles de pobreza y precarios servicios de salud y educación. Esto reforzado por la descentralización en la gestión de estas políticas en los años 90.

A continuación exponemos un cuadro con datos respecto al Índice de Desarrollo Humano de la región, provincia por provincia. Lo cual sabemos hay que observar de manera crítica debido a que frecuentemente estos índices se utilizan para justificar el desarrollo de proyectos extractivos, en lugar del financiamiento o implementación de políticas claves como lo son la salud, la educación y el empleo.

Cuadro: IDH de las Unidades Administrativas sub-nacionales en el EID Capricornio

\begin{tabular}{|c|c|c|c|c|c|c|}
\hline Pais & Tipo UA & UA & $\begin{array}{c}\text { Ranking IDH } \\
\text { (Provincial, } \\
\text { Departamental } \\
\text { o Estado) (6) }\end{array}$ & $\begin{array}{l}\text { Nivel de } \\
\text { IDH (7) }\end{array}$ & IDH Pais (8) & $\begin{array}{c}\text { Posición IDH } \\
\text { pais a nivel } \\
\text { Mundial } 2013 \\
\text { (9) }\end{array}$ \\
\hline \multirow{11}{*}{$\begin{array}{l}\text { ARGENTINA (1) Ranking sobre un total } \\
\text { de } 24 \text { provincias con un rango entre } \\
(0,806-0,889)\end{array}$} & \multirow{11}{*}{ Provincia } & Santa Fe & 10 & Medio & \multirow{11}{*}{0,808} & \multirow{11}{*}{$\begin{array}{c}49 \\
\text { (Muy Alto) }\end{array}$} \\
\hline & & Tucumán & 11 & Medio & & \\
\hline & & Catamarca & 14 & Medio & & \\
\hline & & La Rioja & 15 & Medio & & \\
\hline & & Salta & 16 & Medio & & \\
\hline & & Jujuy & 17 & Medio & & \\
\hline & & Corrientes & 18 & Medio & & \\
\hline & & Misiones & 21 & Bajo & & \\
\hline & & Chaco & 22 & Bajo & & \\
\hline & & Santiago del Estero & 23 & Bajo & & \\
\hline & & Formosa & 24 & Bajo & & \\
\hline
\end{tabular}

Fuente: Documento de caracterización socio económica y ambiental del Eje de Capricornio - IIRSA 
Artigo original

Hegemonia - Revista Eletrônica de Relações Internacionais do Centro Universitário Unieuro

ISSN: 1809-1261

UNIEURO, Brasília, número 20, Janeiro-Junho de 2017, pp. 89-119.

Territorios del Norte argentino en disputa: modelos extractivistas e infraestructura

Como ha sido expuesto al principio de este trabajo, el recorte espacial del mismo se realizará en el Norte argentino, debido a que las provincias que participan de la zona de influencia de la ZICOSUR son las provincias que corresponden a la región del Norte argentino.

El Informe de 2015 de la Cámara Argentina de Comercio nos presenta los perfiles exportadores de cada provincia argentina, exponiendo el perfil primario exportador de las economías norteñas ${ }^{11}$.

El documento realizado con el fin de analizar los aspecto socioeconómicos y ambientales de los proyectos de IIRSA, explica que la red de proyectos de COSIPLANIIRSA $^{12}$ se concentran en el territorio central del Eje, principalmente en las unidades administrativas de Argentina, ello con una clara intención de fortalecer la trama de infraestructura que provee conectividad hacia la costa del Atlántico y Pacífico, logrando así consolidar progresivamente la condición de corredor bioceánico que potencialmente presenta el EID Capricornio (COSIPLAN-IIRSA, 2015).

11 Respecto a la provincia de Catamarca, se encuentran entre sus principales productos exportados los minerales de cobre y sus concentrados $(87,79 \%)$, siendo el principal destino de esas exportaciones Alemania $(38,22 \%)$ y Japón $(18,20 \%)$ (CAC, 2015).

Cuando se observa la provincia de La Rioja, se encuentra que los productos principales son el papel y cartón, recubiertos de polietileno, estratificados con aluminio, impresos (34,88\%) y las aceitunas $(14,41 \%)$ y cueros (10,08\%). Teniendo como principal destino a Chile (21,33\%) y Brasil (16,44\%) (CAC, 2015).

Cuando se muestran los porcentajes de Salta, los productos que más se exportan son nafta $(21,25 \%)$, otros aceites combustibles $(11,08 \%)$ y tabaco $(10,33 \%)$. Y los principales países a los que exporta son Brasil (32,29\%), Bolivia (11,81\%) y China (9,83\%) (CAC, 2015).

Respecto a Jujuy, sus productos más exportados son minerales de metales preciosos y sus concentrados $(22,48 \%)$, tabaco $(18,93 \%)$ y minerales de plomo y sus concentrados $(11,00 \%)$. Siendo los principales destinos de las exportaciones de esta provincia Bélgica (24,63\%), China (17,51\%) y Brasil (14,21\%) (CAC, 2015).

En el caso de Tucumán, los principales productos exportados son los limones y limas $(20,16 \%)$, los aceites esenciales de limón (15,64\%) y los jugos de cítricos (11,55\%). Los países a cuales van esos productos, entre otros, son Brasil (20,69\%) y Estados Unidos (12,45\%) (CAC, 2015).

Santiago del Estero, tiene entre sus principales productos exportados al maíz en grano $(36,24 \%)$ y habas de soja (27,57\%). Siendo sus principales destinos de exportación China (23,12\%) y Chile (7,25\%) (CAC, 2015).

12 El Consejo Suramericano de Infraestructura y Planeamiento (COSIPLAN), es una instancia de discusión política y estratégica, a través de la consulta, evaluación, cooperación, planificacióny coordinación de esfuerzos y articulación de programas y proyectos para implementar la integración de la infraestructura regional de los países Miembros de la UNASUR. Su creación fue decidida en la III Reunión Ordinaria del Consejo de Jefas y Jefes de Estado y de Gobierno, conforme al Tratado Constitutivo de la UNASUR (UNASUR, 2009). 
Artigo original

Hegemonia - Revista Eletrônica de Relações Internacionais do Centro Universitário Unieuro

ISSN: $1809-1261$

UNIEURO, Brasília, número 20, Janeiro-Junho de 2017, pp. 89-119.

Dentro de la Agenda de Proyectos Prioritarios de IIRSA $^{13}$ se encuentran una serie de proyectos en etapa de ejecución y de pre-ejecución que involucran a los territorios de las provincias del norte argentino.

13 Proyecto Conexión Oeste Argentina-Bolivia / Código 10, en Etapa de pre-ejecución. Este proyecto estructurado está conformado por los siguientes proyectos individuales: i) Rehabilitación del Ferrocarril Jujuy - La Quiaca; ii) Pavimentación de la Ruta Nacional No 40 Corredor Minero (límite con Bolivia) iii) Puente Binacional y Centro de Frontera La Quiaca (Ar) - Villazón (Bo).

El recorrido ferroviario comienza en la ciudad de Jujuy hasta el extremo Noroeste de Argentina en la localidad de La Quiaca, donde se conecta con la localidad de Villazón en Bolivia por el actual puente ferroviario, la traza continúa en territorio boliviano llegando hasta Oruro. Por otra parte, el nuevo puente y centro de frontera proyectado entre las ciudades fronterizas estaría cercano al Puente Internacional existente. Con relación a la nueva traza de la $\mathrm{RN} \mathrm{N}^{\circ} 40$ en la Provincia de Jujuy (Corredor Minero) tiene su inicio en San Antonio de los Cobres en la Provincia de Salta (en proximidades del límite con la Provincia de Jujuy), atravesando una serie de localidades y culminando su recorrido en La Quiaca (límite con Bolivia). [Ficha Técnica del Proyecto http://www.iirsa.org/proyectos]

Otro de los proyectos se denomina CORREDOR FERROVIARIO BIOCEÁNICO PARANAGUÁ ANTOFAGASTA / Código 11. Actualmente el proyecto se encuentra en la Etapa de Ejecución. Este proyecto tiene por objeto proporcionar una conexión ferroviaria multilateral para el transporte de cargas en el Eje de Capricornio entre los territorios considerados, en una traza que va desde el puerto de Antofagasta, en Chile, pasando por el norte argentino y por Paraguay, siguiendo por el territorio brasileño hasta el puerto de Paranaguá.

El corredor bioceánico busca reducir los costos logísticos de media y larga distancia y fomentar los intercambios comerciales. La existencia del corredor permitirá el intercambio de mercaderías entre las márgenes oriental y occidental del continente sirviendo para transportar los crecientes flujos de importación y exportación de y para Suramérica, sea por el Atlántico o por el Pacífico. La facilidad de acceso deberá generar impacto positivo a la integración de cadenas productivas y logísticas, principalmente en granos, carnes y procesamiento de minerales.

El proyecto apunta a consolidar una red de conectividad de alcance regional integrando las redes ferroviarias existentes y consolidando su unidad física y operacional.

También considera las obras complementarias, así como las demás condiciones estructurales, normativas y técnicas, de seguridad y procedimientos que permitan asegurar una total continuidad de los flujos y una efectiva integración de todos sus tramos.

En líneas generales, los sistemas ferroviarios son antiguos y se encuentran deteriorados, constituyendo una limitación para el traslado de trenes de mayor tamaño. Por ello, el proyecto es muy importante pues permitiría incrementar las economías de escala propias de este modo de transporte.

Los nueve proyectos individuales que conforman este proyecto estructurado están orientados a rehabilitar líneas férreas existentes, a ejecutar tramos que son eslabones faltantes y a reforzar u optimizar puentes y patios de cargas, resultando en un ferrocarril con trocha de $1 \mathrm{~m}$ que interconectará los cuatro países y los océanos Pacífico y Atlántico.

Tres proyectos están localizados en Argentina y con intervenciones para rehabilitar vías férreas: i) Rehabilitación del Ramal Ferroviario C3: Resistencia - Avia Terai - Pineo; ii) Rehabilitación del Ramal Ferroviario C12: Avia Terai - Metán; y iii) Rehabilitación del Ramal Ferroviario C14: Salta - Socompa. Dos proyectos están en territorio brasileño: i)

Construcción del tramo Cascavel - Foz de Iguaçu; y ii) Adecuación del tramo Paranaguá - Cascavel y construcción de la variante ferroviaria entre Guarapuava e Ingeniero Bley. Uno en Chile: Corredor Ferroviario Bioceánico tramo Chile (Antofagasta - Socompa). Uno en Paraguay: Construcción de la Ferrovía Ciudad del Este - Pilar. Un proyecto articula a Argentina y Paraguay: Optimización del nodo Puente Ñeembucú - Río Bermejo. Y 
Hegemonia - Revista Eletrônica de Relações Internacionais do Centro Universitário Unieuro

ISSN: $1809-1261$

UNIEURO, Brasília, número 20, Janeiro-Junho de 2017, pp. 89-119.

Cuadro № 2.2: UA que integran el EID Capricornio en territorio de Argentina

\begin{tabular}{|c|c|c|c|c|c|}
\hline País & Tipo UA & UA & Capital & Principales Ciudades & Pasos de frontera \\
\hline \multirow{11}{*}{ ARGENTINA } & \multirow{11}{*}{ Provincia } & Corrientes & Corrientes & La Paz, Mercedes & $\begin{array}{l}\text { Paso de los Libres, Santo } \\
\text { Tomé, Yaciretá }\end{array}$ \\
\hline & & Chaco & Resistencia & $\begin{array}{l}\text { Presidencia Roque Saénz Peña, } \\
\text { Villa Ángela, }\end{array}$ & \\
\hline & & Formosa & Formosa & Clorinda & $\begin{array}{l}\text { Clorinda, Pasarela, } \\
\text { Colonia General Belgrano, } \\
\text { Isleta, El Remanso, } \\
\text { Lamadrid }\end{array}$ \\
\hline & & Misiones & Posadas & Oberá, El Dorado, Puerto Iguazú & $\begin{array}{l}\text { Posadas, İuazú, } \\
\text { Andresito, Integración, } \\
\text { San Antonio, Bernardo de } \\
\text { Irigoyen, Pepiri Guazú }\end{array}$ \\
\hline & & Santa Fe & Santa Fe & $\begin{array}{l}\text { Rosario, Rafaela, Reconquista, } \\
\text { Villa Constitución }\end{array}$ & \\
\hline & & Catamarca & $\begin{array}{l}\text { San Fernando del Valle de } \\
\text { Catamarca }\end{array}$ & & San Francisco \\
\hline & & Salta & Salta & & $\begin{array}{l}\text { Salvador Mazza, Aguas } \\
\text { Blancas, El Condado, Sico, } \\
\text { Socompa, Misión La Paz }\end{array}$ \\
\hline & & Jujuy & San Salvador de Jujuy & La Quiaca & La Quiaca, Jama \\
\hline & & Santiago del Estero & Santiago del Estero & La Banda & \\
\hline & & Tucumán & San Miguel de Tucumán & Concepción, Banda del Río Sali & \\
\hline & & La Rioja & La Rioja & & Pircas Negras \\
\hline
\end{tabular}

Fuente: Documento IIRSA sobre el Eje de capricornio

En el Acta Final de la Comisión de Infraestructura y Servicios Conexos, de la reunión de ZICOSUR en Santa Cruz de la Sierra, Bolivia en el año 2006, quedan sentadas ciertas acciones a seguir por parte de los miembros del bloque. Entre las que se destacan en general, y en particular, involucran a las provincias del norte argentino. Por otra parte definen: Impulsar

un proyecto articula a Brasil y Paraguay: Puente Ferroviario con Patio de Cargas (Ciudad del Este - Foz de Iguazú). [Ficha Técnica del Proyecto http://www.iirsa.org/proyectos]

Por último, otro de los proyectos que IIRSA incluye en su agenda de proyectos prioritarios y que tienen como Área de Influencia al territorio del norte argentino, es el Gasoducto del Noreste Argentino / Código 25. Este proyecto se encuentra en Etapa de Preejecución.

La propuesta es construir un sistema de transporte de gas que parte desde Bolivia, comprendiendo 1500 $\mathrm{km}$ aproximadamente del ramal troncal que atraviesa las provincias argentinas del Chaco, uniendo los tramos ubicados en Formosa y Santa Fe, con sus derivaciones que permitirá el desarrollo de las localidades del interior provincial.

La obra comprenderá: i) el Gasoducto Troncal y los ramales provinciales que derivarán de él; ii) las plantas compresoras y de regulación y medición; iii) las instalaciones de superficie y otras obras complementarias de carácter civil, eléctrico y de comunicaciones. Las obras complementarias incluirán la implementación de los sistemas de transmisión electrónica de datos, la operación a distancia, la telemetría, etc.

Se encuentran en ejecución los trabajos para la primera etapa de la obra, representan una inversión de 500 millones de dólares, para 798 kilómetros en 24 pulgadas, de los que en Salta están en ejecución 230 kilómetros, en Formosa otros 303 y en el norte de Santa Fe 265 kilómetros. Respecto a la segunda etapa la misma se inició en la provincia de Chaco con una extensión de $172 \mathrm{~km}$ llegando a la provincia de Santa Fé.[ Ficha Técnica del Proyecto http://www.iirsa.org/proyectos] 
Hegemonia - Revista Eletrônica de Relações Internacionais do Centro Universitário Unieuro

ISSN: $1809-1261$

UNIEURO, Brasília, número 20, Janeiro-Junho de 2017, pp. 89-119.

la habilitación de las redes ferroviarias de la regional por cada uno de los corredores existentes, Instar a los responsables de IIRSA para que en la próxima reunión se presenten los Términos de Referencia para los proyectos de Estudio Ferroviario vinculación bioceánica - área ZICOSUR (ZICOSUR, 2006).

En la reunión realizada en Antofagasta en 2007, estuvo presente Claudio Flores, representante del IIRSA, quien entregó un avance en materia de financiamiento dentro del marco del Zicosur a los proyectos de acuerdo a la metodología del IIRSA. Además, se mostraron los informes respecto a las obras concluidas para el Paso San Francisco, que involucra a la provincia de Catamarca del lado argentino, cuyo representante estuve presente.

IIRSA y ZICOSUR: integración extractivista/neoextractivista

Ana Ceceña et al. (2007) explica que el neoliberalismo "llegó acompañado de su propia manera de apropiarse de los territorios y refuncionalizar el espacio” (CECEÑA ET AL., 2007, p. 10). Esa manera particular es presentada por la autora en tres momentos: los planes económicos de liberalización como el Tratado de Libre Comercio de América del Norte, el Tratado de Libre Comercio de Centroamérica y República Dominicana y el proyecto del Área de Libre Comercio de las Américas. Otro momento es el de los planes de control militar y por último hace mención a los megaproyectos de infraestructura (CECEÑA ET AL., 2007).

[...] es el que busca trazar nuevas rutas, adecuadas a la geografía económica del siglo xxi: las nuevas venas abiertas hacia el imperio que responden a nuevas necesidades y a una diferente selección de las materias primas y los llamados recursos estratégicos. Caminos que conecten los grandes centros de producción y consumo del mundo, que abaraten y aceleren los traslados y que al mismo tiempo refuercen la vigilancia y el control sobre los mismos es el objetivo. Hacer fluir el corazón de las selvas o las profundidades de las minas hacia los centros industriales y, a la inversa, llevar el espíritu industrial y competitivo hasta el centro de las selvas y minas. Agilizar los desplazamientos diversificando sus medios: ferrocarriles, autopistas, ríos, canales y cables de fibra óptica. Transformar el territorio. Adecuarlo a las nuevas mercancías, a las nuevas tecnologías y los nuevos negocios. Cuadricularlo, ordenarlo, hacerlo funcional y... productivo. Ese es el modo capitalista de entender la naturaleza y relacionarse con ella (CECEÑA ET AL, 2007, p. 12-13). 
Hegemonia - Revista Eletrônica de Relações Internacionais do Centro Universitário Unieuro

ISSN: 1809-1261

UNIEURO, Brasília, número 20, Janeiro-Junho de 2017, pp. 89-119.

Eduardo Gudynas explica estas iniciativas entre sus "Diez tesis sobre el neoextractivismo" en la región. En su quinta tesis expone que "bajo el nuevo extractivismo persiste la fragmentación territorial en áreas desterritorializadas, generándose un entramado de enclaves y sus conexiones a los mercados globales, que agravan las tensiones territoriales" (Gudynas, 2009, p. 201).

Los cambios territoriales bajo el extractivismo aunque pueden ser localizados, son profundos, ya que modifican la configuración del espacio, los actores que lo construyen y sus formas de relación. En escalas geográficas mayores, en casi todos los casos, el neoextractivismo está apoyado en la IIRSA, que es activamente promovida por todos los gobiernos progresistas, bajo un liderazgo de Brasil. Esos emprendimientos, sumados a las acciones nacionales, desencadenan esa reconfiguración de los territorios.

El avance de la explotación minera, petrolera o los monocultivos de exportación desencadena profundos impactos territoriales. En muchos casos representan la llegada de contingentes de operarios y técnicos, y sus equipos, a áreas remotas; algunas de ellas están habitadas por comunidades rurales o pueblos indígenas ${ }^{14}$. Generan enclaves productivos que están conectados por corredores de transporte o de energía con otras zonas del país, y orientados hacia los puertos de exportación.

Sus actividades son resguardadas en muchos casos por el propio Estado, incluso por medio de protección policial o militar. Muchos de esos enclaves son un ingrediente más en un proceso de fragmentación geográfica, especialmente en las zonas andinas y amazónicas. Mientras que en ellos se expresa fuerte presencia estatal, están rodeados de amplias regiones "desterritorializadas", donde el Estado no logra asegurar su presencia en forma adecuada y

14 Según el INDEC. (Instituto Nacional de Estadísticas y Censos de Argentina) el Censo Nacional de Población, Hogares y Vivienda 2010 registra que en Argentina habitan 955.032 personas pertenecientes a comunidades originarias. Para el Área de Influencia del Eje de Capricornio (región del norte argentino) se han identificado al menos 17 comunidades, ubicadas mayormente en las provincias de Salta, Jujuy, Formosa y Tucumán, también hay presencia a la vera del río Paraná correspondiente a la provincia de Santa Fe y la provincia de Misiones. Estas son las pertenecientes a los pueblos Mbyá Guaraní, Charrúa, Mocoví, Mocoví toba, Diaguita, Diaguita Calchaquí, Diaguita Cacano, Toba Qom, Comechingón, Pilagá, Kolla Guaraní, Ava Guaraní, Atacama, Wichi, Omaguaca, Lule, y Lule Vilela. 
Artigo original

Hegemonia - Revista Eletrônica de Relações Internacionais do Centro Universitário Unieuro

ISSN: $1809-1261$

UNIEURO, Brasília, número 20, Janeiro-Junho de 2017, pp. 89-119.

homogénea, observándose limitaciones por ejemplo en la cobertura de los derechos ciudadanos, los servicios de salud o la aplicación de la justicia. Es un Estado débil o ausente en muchas de esas áreas, pero activo y presente en apoyar y proteger actividades extractivas en unos pocos sitios. Los enclaves extractivos generan muchas tensiones y contradicciones.

En unos casos, los gobiernos asignan bloques de exploración y explotación que ignoran los territorios preexistentes, reconocidos por pueblos indígenas o comunidades campesinas. En otros casos, explica Gudynas (2009) esos enclaves significan la apertura de zonas remotas o el avance de la frontera agropecuaria, y junto con ella, el ingreso de cazadores furtivos, tala ilegal del bosque, narcotráfico, o contrabando, por lo cual las condiciones de seguridad se deterioran y la violencia aumenta.

A su vez, los enclaves extractivos requieren redes de conectividad que permitan la entrada de insumos y equipamientos, y la salida de los productos exportables, lo que a su vez desencadena otros impactos. En algunos grandes emprendimientos se hacen necesarias significativas obras de apoyo en infraestructura o energía (incluso represas hidroecoeléctricas o provisión de gas), las que a su vez generan otros impactos territoriales.

Conflictos socio-ambientales: avanza el extractivismo, avanza la resistencia

En los diversos casos que se han desarrollado conflictos en Argentina han tenido las siguientes características que Merlinsky expone,

[...] las disputas se presentan en escenarios locales, ejerciendo una presión mayor sobre los gobiernos provinciales y los municipios. Los grupos de autoconvocados y las asambleas ciudadanas ambientales son los repertorios organizativos que se han desarrollado al calor de estos conflictos. Se trata de un formato de acción colectiva que se instaló durante la crisis institucional de 2001 y que tiene plena vigencia como forma de articulación de los diferentes actores sociales, políticos y económicos que reclaman por afectaciones al territorio y al ambiente. En la dinámica contenciosa se vuelven un espacio de experimentación y un lugar de producción de marcos interpretativos. Los vecinos que participan en estas experiencias organizan colectivamente y ponen en escena esquemas de interpretación que permiten 
Artigo original

Hegemonia - Revista Eletrônica de Relações Internacionais do Centro Universitário Unieuro

ISSN: $1809-1261$

UNIEURO, Brasília, número 20, Janeiro-Junho de 2017, pp. 89-119.

localizar, percibir e identificar eventos y situaciones, en vista a organizar la experiencia y orientar la acción (MERLINSKY, 2013, p. 29).

Realizaremos el análisis de lo presentado anteriormente, partiendo de la perspectiva de la ecología política, que Arturo Escobar define citando a Joan Martinez Alier (2002),

[...] la ecología política como el estudio de los conflictos de distribución ecológica. Se refiere a conflictos sobre el acceso y el control de los recursos naturales particularmente como una fuente de subsistencia, incluyendo los costos por la destrucción del medio ambiente. En muchas partes, los grupos locales se involucran en luchas en contra de las fuerzas translocales de diversos tipos para defender su lugar (ESCOBAR, 2011, p. 66).

Estos conflictos se enmarcan en lo que Maristella Svampa denomina el "giro eco-territorial",

[...] dentro del cual convergen la filosofía del "vivir bien" con una visión ecológica, de respeto del medio ambiente. Dicho giro eco-territorial no es privativo de aquellos países en los cuales existe una fuerte presencia de pueblos originarios, históricamente excluidos, sino que abarca también otros, como la Argentina, donde en los últimos años se han multiplicado las resistencias campesino - indígenas y, sobre todo, los movimientos socioambientales (SVAMPA, 2011, p. 182).

En la misma línea, Svampa cita a la distinción que realiza Martinez Alier (2004) respecto a "tres corrientes del ecologismo: el culto de la vida silvestre, el creo ecoeficientista y el movimiento de justicia ambiental",

La primera corriente se preocupa por la preservación de la naturaleza silvestre; es indiferente u opuesta al crecimiento económico, valora negativamente el crecimiento poblacional y busca respaldo científico en la biología de la conservación. De ahí que su accionar se encamine a crear reservas y parques naturales en aquellos lugares donde existen especies amenazadas o sitios caracterizados por la biodiversidad. Grandes internacionales conservacionistas, muchas veces poco respetuosas de las poblaciones nativas, se instalan en este registro biocéntrico (SVAMPA, 2011, p. 188).

Svampa continúa exponiendo la segunda corriente que se encuentra vinculada con el mundo de las ONGs, y a lo que denomina como eco-eficientismo, que postula el eficiente uso de los recursos naturales y el control de la contaminación. "Sus conceptos clave son "modernización ecológica", "desarrollo sustentable" y, de manera más reciente, “industrias limpias”, entre otras.” (SVAMPA, 2011, p. 188-189). 
Hegemonia - Revista Eletrônica de Relações Internacionais do Centro Universitário Unieuro

ISSN: 1809-1261

UNIEURO, Brasília, número 20, Janeiro-Junho de 2017, pp. 89-119.

Por último, explica que la tercera posición es la que representa el movimiento de justicia ambiental, o lo que Martinéz Alier designó como “ecología popular”, "corriente que crece en importancia y coloca el acento en los conflictos ambientales, que en diversos niveles (local, nacional, regional), son causados por la reproducción globalizada del capital, la nueva división internacional y territorial del trabajo y la desigualdad social" (SVAMPA, 2011, p. 189).

Entre los actores en conflicto postulamos que se encuentran los modelos de integración por un lado IIRSA-ZICOSUR y por el otro, la Unión de Asambleas Ciudadanas, espacio que articula a las poblaciones locales. Los primeros, se encuentran regidos por lo que Leff (2004) postula como la racionalidad moderna. La racionalización económica del mundo, fundada en el proyecto científico de la modernidad, ha llegado a escudriñar los núcleos más íntimos de la naturaleza. Sin embargo, Leff (2004) continua afirmando que los conocimientos basados en esa racionalidad que cosifica al mundo, desde una visión utilitarista e instrumental de la naturaleza, se encuentra en crisis y frente a la misma, emerge una racionalidad alternativa con carácter emancipatorio, crítico y transformador.

La racionalidad ambiental orienta las acciones sociales por los principios de la sustentabilidad, la autonomía, la autogestión, la democracia, la equidad y la participación. No es una racionalidad ecológica ceñida a los valores intrínsecos de la naturaleza que tanto reclaman el biocentrismo y el conservacionismo. De esta manera, las comunidades indígenas y campesinas están asociando sus luchas por legitimar sus derechos culturales con demandas por el acceso y la apropiación de la naturaleza, en las que subyacen estructuras de poder, valores culturales y estrategias productivas alternativas. La racionalidad ambiental orienta las acciones sociales por los principios de la sustentabilidad, la autonomía, la autogestión, la democracia, la equidad y la participación (Leff, 2004, p. 454). 
Hegemonia - Revista Eletrônica de Relações Internacionais do Centro Universitário Unieuro

ISSN: 1809-1261

UNIEURO, Brasília, número 20, Janeiro-Junho de 2017, pp. 89-119.

Las racionalidades otras, emergen en un contexto de profundización del modelo extractivista, acompañado de las políticas de integración orientadas a la infraestructura, y la Unión de Asambleas Ciudadanas es un ejemplo de ellas. Estas asambleas configurarn un espacio donde se busca profundizar la unidad para la organización, un encuentro entre las luchas cotidianas de las distintas regiones del país frente a las megamineras, las pasteras, las represas, las petroleras, los monocultivos, los agrotóxicos, la deforestación de bosques, la contaminación urbano industrial, la destrucción de los humedales, los megaemprendimientos inmobiliarios, los planes de integración para el saqueo, la privatización y extranjerización de la tierra, la expropiación de territorios a comunidades originarias, con sus avances depredadores del medio ambiente, la cultura y las comunidades. Entre sus consignas se encuentra el NO a la Iniciativa para la Integración de Infraestructura Regional Sudamericana (IIRSA) y SI a la integración de los pueblos hermanos y articulación de las luchas. (Documento Oficial de la UAC, 2011, p. 9).

La UAC, podría considerarse dentro de los movimientos ambientalistas por la recuperación social de la naturaleza, que Enrique Leff (2004) plantea que emergen de la crisis ambiental -y del Estado- la cual ha causado destrucción ecológica, degradación ambiental, marginación social y creciente pobreza. Leff, expone que esas consecuencias fueron desarrolladas por la racionalización económica del mundo, pero que al mismo tiempo están impulsando la construcción de identidades colectivas y expresiones de solidaridad inéditos en la organización social.

Las organizaciones socioambientales tienden a asociarse en redes de agrupaciones autónomas, segmentadas y policéfalas, en estructuras no jerárquicas, descentralizadas y participativas. Estos nuevos movimientos se caracterizan por sus nuevas demandas de participación social, la obtención de bienes simbólicos y la recuperación de estilos tradicionales de vida, pero también por la defensa de nuevos derechos étnicos y culturales, ambientales y colectivos, y la reivindicación de su ancestral patrimonio de recursos ambientales. Sus luchas por la dignidad y la democracia, contra el sometimiento y sobreexplotación de grupos sociales, lo son al mismo tiempo por un derecho de reapropiación de sus territorios y de autogestión de sus recursos naturales. (Leff, 2004, p. 398). 
Hegemonia - Revista Eletrônica de Relações Internacionais do Centro Universitário Unieuro

ISSN: $1809-1261$

UNIEURO, Brasília, número 20, Janeiro-Junho de 2017, pp. 89-119.

Sin embargo, ellos y ellas mismos/as -los y las miembros/as de la UAC- se consideran como un movimiento territorial, como expresa en una entrevista ${ }^{15}$ Jenny Lujan $^{16}$,

[...] respecto al ambientalismo, nunca nos definimos así. Somos un movimiento territorial y eso lo tuvimos siempre en claro, no nos interesa ser ecologistas ni nada de eso, más allá de que nos interese muchísimo la ecología. Pero lo que nosotros defendemos es mucho más que lo ambiental: estamos defendiendo los bienes comunes, los recursos naturales, el patrimonio, y eso es territorio. Somos un movimiento territorial porque estamos defendiendo nuestra identidad, nuestra cultura, nuestra soberanía, la autodeterminación de nuestro pueblo, y todo eso es territorio (Jenny Lujan, 2013).

Así, postulando los intereses de los actores que son parte de las disputas por un determinado territorio, es que pretendemos mostrar como en una región de la periferia del país argentino, donde las iniciativas de "desarrollo" e "integración" en los últimos años se han concentrado en proyectos de características extractivistas, no es casualidad que los gobiernos provinciales estén articulando con el sector empresarial de la región, obras de infraestructura que traigan beneficios para el mercado y no para la población.

\section{Consideraciones finales}

Concluimos nuestro trabajo esbozando algunas reflexiones sobre la integración para infraestructura como lo representa la ZICOSUR, y sus objetivos, que se encuentran claramente influenciados por el contexto de las políticas neoliberales, caracterizadas por un Estado que promueve mayor presencia del mercado, los empresarios y la descentralización, permitiendo un protagonismo a los gobiernos locales. Por otra parte, también puede observarse como el paradigma del Regionalismo Abierto de la CEPAL, puede ejemplificarse en la prioridad comercial que articula al bloque y sus fines de "abrir caminos", a través de la infraestructura, a las regiones periféricas.

15 La entrevista fue publicada por primera vez en el $\mathrm{N}^{\circ} 5$ de la Revista Nuestra Voz, editada por el Movimiento Popular La Dignidad con la cual tuve contacto en el XVIII Encuentro Nacional de Mujeres realizado en 2013 en la provincia de San Juan, Argentina.

16 Referente de las asambleas riojanas contra la megamineria en la provincia de La Rioja, Argentina. 
Hegemonia - Revista Eletrônica de Relações Internacionais do Centro Universitário Unieuro

ISSN: $1809-1261$

UNIEURO, Brasília, número 20, Janeiro-Junho de 2017, pp. 89-119.

En segundo lugar, sus perfiles productivos exportadores, muestran que las provincias del norte argentino exportan productos principalmente primarios, sin pasar por un proceso de industrialización, en la que en la mayoría de los casos son actividades extractivas a gran escala, como la minería en la provincia de Catamarca. Esto presenta a esta región como rica en recursos naturales, objeto de proyectos extractivistas, los cuales en su mayoría tienen como destino de exportación países como China y Brasil. Al mismo tiempo que estas provincias son caracterizadas por un medio y bajo nivel de desarrollo humano. Siendo expuestas, y ofrecidas, al mundo como "la periferia de la periferia".

Estos fundamentos que exponen a la región del norte argentino como rica en recursos naturales, pero con su población sumida en la pobreza, fundamenta el oportunismo de mega proyectos extractivos e infraestructura. Siendo la integración, en este caso subregional, una herramienta que más que desarrollo, es funcional a perpetuar el rol de exportadores de materias primas y alimentos que cumplen estos países -y sus respectivas unidades subnacionales- en la división internacional/territorial del trabajo.

Entonces, observando la relación de ZICOSUR e IIRSA en lo que refiere a esta región de Argentina - y al resto de miembros del bloque subregional- consideramos que se encuentran construidos bajo la racionalidad que tiene como objetivo el progreso eterno, a cualquier costo. Esto puede verse en quienes son los interesados en el desarrollo de espacios como ZICOSUR. Empresarios, o incluso países que se encuentran fuera del continente, del otro lado del Pacífico. En lugar de ser, las mismas sociedades que habitan esos territorios los que promuevan esas iniciativas u otras, regidas por una racionalidad alternativa.

Así, entendemos a la integración en una fase extractivista/neoextractivista, dependiendo de los gobiernos que trabajen como actores principales, encontrando provincias, estados, departamentos y regiones, que son parte de diversos países, integradas para desarrollar proyectos de infraestructura que terminen fragmentando más a las poblaciones, afectando su soberanía alimentaria, saqueando y contaminando sus bienes comunes y el territorio donde viven, generando al mismo tiempo conflictos socio-ambientales, de los cuales emergen nuevos sujetos en resistencia. 
Artigo original

Hegemonia - Revista Eletrônica de Relações Internacionais do Centro Universitário Unieuro

ISSN: $1809-1261$

UNIEURO, Brasília, número 20, Janeiro-Junho de 2017, pp. 89-119.

Referencias bibliográficas

ACOSTA, Alberto. De cómo el extractivismo oprime el cerebro de nuestras sociedades. Algunas anotaciones al caso ecuatoriano. Boletín Onteaiken No 15 _ Mayo 2013.

ATACALAR: http://www.comiteatacalar.cl/

BRUCULO, Celia Romina - Becaria CONICET- USAL-UNLAR, "Paradiplomacia en el MERCOSUR: la integración sub-regional en las alternativas sub-nacionales y dinámicas de integración subyacentes, (ATACALAR -ZICOSUR Mercociudades)". I JORNADAS DE ESTUDIOS DE AMÉRICA LATINA Y EL CARIBE. Universidad de Buenos Aires, 26,27 y 28 de septiembre de 2012 .

CÁMARA ARGENTINA DE COMERCIO. Perfiles Exportadores Provinciales. 2015.

CARLINO, A.; VEIRAVÉ, F. Buscando moderar los efectos de la globalización. La provincia del Chaco y su participación en distintas organizaciones subregionales. VII Jornadas de Historia de las Relaciones Internacionales de la Asociación Argentina de Historia de las Relaciones Internacionales en la FCE-UBA. Octubre de 2013.

CECEÑA, A.; AGUILAR, P.; MOTTO, C. Territorialidad de la dominación: la integración de la infraestructura regional sudamericana (IIRSA). Buenos Aires: Observatorio Latinoamericano de Geopolítica, 2007.

CIPOLETTA TOMASSIAN, Georgina (2009) Edición No 280, diciembre de 2009 En esta edición del Boletín FAL.

Comité de integración fronteriza Chile-Argentina http://www.difrol.gob.cl/argentina/comitede-integracion-chile-argentina.html.

CORVALÁN, Matías Aguilera y VELARDEZ, Mónica. Proyectos de Infraestructura Vial para el comercio exterior en pos de la Integración Regional: Casos Paso de Jama y Sico.

Cuadernillo de la Unión de Asambleas Ciudadanas. "Construyendo Caminos Colectivos en Defensa de Nuestros Territorios". Disponible en línea: http://asambleasciudadanas.org.ar/wp-content/uploads/2012/09/CuadernilloUACparaimprimir.pdf. 
Artigo original

Hegemonia - Revista Eletrônica de Relações Internacionais do Centro Universitário Unieuro

ISSN: 1809-1261

UNIEURO, Brasília, número 20, Janeiro-Junho de 2017, pp. 89-119.

Documento del taller Integración e infraestructura http://www.iirsa.org/admin_iirsa_web/Uploads/Documents/cap_doc_compilado_cu rso08y09.pdf.

Documento trabajado por la CEPAL http://www.iirsa.org/admin_iirsa_web/Uploads/Documents/CEPAL\%20UNASURInfraes tructura $\% 20$ para $\% 201 \mathrm{a} \% 20$ Integraci $\%$ C3\%B3n $\% 20$ Regional.pdf.

Documento de "Amigos de la tierra" Disponible en línea: http://www.natbrasil.org.br/Docs/instituicoes_financeiras/documento_iirsa_desvend ando_interesses.pdf.

Documento sobre el eje de capricornio de IIRSA Disponible en línea: http://www.iirsa.org/admin_iirsa_web/Uploads/Documents/Caracterizaci\%C3\%B3n_EJE _CAPRICORNIO_final.pdf.

ESCOBAR, A. Ecología Política de la Globalidad y la Diferencia. En La naturaleza Colonizada. Ecología política y minería en América Latina.

GARRIDO DE SOLÁ, M. La ZICOSUR es la historia de Salta. Biblioteca provincial Dr. Atilio Cornejo. Disponible en: http://www.biblioatiliocornejo.gov.ar/zicosur.htm.

GARRIDO ROJAS, J. Cambios socio-políticos en el escenario mundial (1945 - 200) Santiago de Chile. Editorial Universitaria. 2001.

GUDYNAS, E. El “regionalismo abierto” de la CEPAL: insuficiente y confuso. Observatorio Hemisférico 28 de septiembre de 2005. Disponible en: http://www.integracionsur.com/americalatina/GudynasRegionalismoAbiertoIrc.pdf.

HARVEY, D. O novo imperialismo. Sao Pablo. Editora Loyola. 2013

http://maristellasvampa.net/archivos/entrevista50.pdf Consultado el 03-05-2015.

IIRSA. Documento sobre el Eje de capricornio Disponible en: http://www.iirsa.org/admin_iirsa_web/Uploads/Documents/Caracterizaci\%C3\%B3n_EJE _CAPRICORNIO_final.pdf.

LEFF, Enrique. El Retorno del Orden Simbólico: La capitalización de la naturaleza y las estrategias fatales del desarrollo sostenible en Racionalidad Ambiental: La reapropiación social de la naturaleza. Enrique Leff. Buenos Aires: Siglo Veintiuno Editores, 2004. 
Hegemonia - Revista Eletrônica de Relações Internacionais do Centro Universitário Unieuro

ISSN: 1809-1261

UNIEURO, Brasília, número 20, Janeiro-Junho de 2017, pp. 89-119.

MERLINSKY, Gabriela Cartografías del conflicto ambiental en Argentina / Gabriela Merlinsky ; compilado por Gabriela Merlinsky. - 1a ed. - Ciudad Autónoma de Buenos Aires : Fundación CICCUS, 2013. ISBN 978-987-693-033-8.

MERLO BLÁZQUEZ, M. Las relaciones internacionales de los actores subnacionales: CRECENEA/CODESUL y ZICOSUR. Trabajos de Investigación en Paradiplomacia, Año1, No. 1. Buenos Aires, Argentina, 2011. ISSN:1853---9939.

OVIEDO, Eduardo Daniel. La proyección de la ZICOSUR en el mundo: el horizonte de cooperación y rivalidad económica con China. I Simposio Electrónico Internacional sobre Política China. Del 1 al 21 de Marzo de 2011. Observatorio de la Política China. España.

Red Mercociudades: http://www.mercociudades.org/.

SAFAROV, A. G. El Territorio como factor dinámico de la integración: LA ZICOSUR. Facultad de Ciencia Política y RR.II. de la UNR, Rosario, Marzo de 2003. Disponible en: http://www.revistapersona.com.ar/Persona21/21Safarov.htm.

SAFAROV, A.; MUSSO, J. La Paradiplomacia en la ZICOSUR (Zona de Integración del

Centro Oeste de América del Sur), diálogo transfronterizo para la inserción en el MERCOSUR. III Congreso de Relaciones Internacionales / International Relations Conference. La Plata, Argentina. Noviembre 2006.

SANTOS, M. A natureza do espaço. São Paulo: Hucitec, 1996.

SANTOS, M. Por uma outra globalização: do pensamento único à consciência universal. 23. ed. Rio de Janeiro: Record, 2013. 174 p. ISBN: 9788501058782.

SANTOS, M. Técnica, espaço e tempo: globalização e médio técnico-científico-informacional. São Pablo. Editora da Universidade do São Pablo. 2013.

SILVEIRA, M. L. Território usado: dinâmicas de especialização dinâmicas de diversidade. Ciência Geográfica - Bauru - XV - Vol. XV - (1): Janeiro/Dezembro - 2011.

SVAMPA, M. Modelos de desarrollo, cuestión ambiental y giro ecoterritorial. En La naturaleza Colonizada. Ecología política y minería en América Latina.

SVAMPA, Maristella. "Consenso de los Commodities” y lenguajes de valoración en América Latina. revista Nueva Sociedad No 244, marzo-abril de 2013, ISSN: 0251-3552. 
Hegemonia - Revista Eletrônica de Relações Internacionais do Centro Universitário Unieuro

ISSN: $1809-1261$

UNIEURO, Brasília, número 20, Janeiro-Junho de 2017, pp. 89-119.

SVAMPA, Marostella, En Argentina hay Neocolonialismo al interior del propio país” VOCES. 2012.

UAC. Cuadernillo de la Unión de Asambleas Ciudadanas. "Construyendo Caminos Colectivos en Defensa de Nuestros Territorios". Disponible en línea: http://asambleasciudadanas.org.ar/wp-content/uploads/2012/09/CuadernilloUAC-paraimprimir.pdf Consultado el 20-07-2015.

UNASUR, Estatuto del Consejo Suramericano de Infraestructura y Planeamiento, 2009. http://www.iirsa.org/admin_iirsa_web/Uploads/Documents/cosiplan_estatuto.pdf.

URIBURU, V. T. 2008 Disponible en: http://japon-hoy.com.ar/entrevistas/fundacionokita/ VAZQUEZ PALACIO, F. La ZICOSUR y la emergencia dirigida de las regiones periféricas: integración y economías subordinadas.

ZICOSUR, Acta de Reunión de la Comisión de Infraestructura y Servicios Conexos. Santa Cruz de la Sierra, Bolivia. 2006.

ZICOSUR, Acta de Reunión de la Comisión de Infraestructura y Servicios Conexos. Antofagasta. 2007.

ZICOSUR. Acta de Reunión Extraordinaria de la Comisión de Infraestructura y Servicios Conexos. Agosto de 2008. San Salvador de Jujuy, Argentina. Disponible en: http://www.zicosur.org.ar/Nueva_ZICOSUR/documentos/Acta\%20Jujuy\%20Infraestructu ra.pdf.

ZICOSUR. Infraestructura y conexiones de la ZICOSUR. Disponible en: http://www.zicosur.org.ar/Nueva_ZICOSUR/espanol/conexiones.htm. 